\section{Análise das políticas públicas: uma proposta metodológica para o estudo no campo da prevenção em Aids}

\section{Public policies assessment: a methodological proposal for the study in the field of Aids prevention}

Juliana Sampaio 1

José Luis Araújo Jr 2

1,2 Departamento de Saúde Coletiva. Centro de Pesquisa Aggeu Magalhães, Campus da Universidade Federal de Pernambuco. Av. Moraes Rêgo, s.n. Cidade Universitária. Recife, PE, Brasil. CEP: 50.670-420. E-mail: juliana@cpqam.fiocruz.br

\begin{abstract}
Public policies are the response of public power to social issues. They are very relevant strategies to face AIDS and the development of prevention measures concerning HIV infection, for they institutionalize systematic actions in the public health sector with this purpose. They are structured in a network of directives that establish the routes to be followed by public officials. Within this context, different actors are part of the game, with different interests and social and political bargaining powers, world concepts negotiation, actions strategies within the field of social rights and duties. It's a struggle of knowledge and interests in the political ground permeated by social, cultural and economic aspects. Therefore, this paper engages in a concept discussion of the theme, developing a theoretical concept of policies assessment from the viewpoint of a methodological study comprising the following: actors, content, context and process, process circumscribing specific agenda designing processes, policy formulation and implementation. This theoretical scenario is developed focusing on the theme of AIDS prevention, the context being the Brazilian environment from which some of the constraints of policies proposals are listed and linked to specialists'considerations pursuing a reorientation of public interventions concerning AIDS prevention.
\end{abstract} Key words Public policies, Acquired Immuno-deficiency Syndrome

\section{Resumo}

As políticas públicas são respostas do poder público para problemáticas sociais. Elas são estratégias de grande relevância para o enfrentamento da Aids e desenvolvimento de ações de prevenção da infecção do HIV, pois institucionalizam no setor público de saúde ações sistemáticas para esse fim. Elas se estruturam numa rede de determinantes que delineiam os caminhos a serem trilhados pelo gestor público. Nesse contexto, entram em jogo diversos atores, com diferentes interesses e poder de barganha político-econômica, negociação de concepções de mundo, estratégias de ação e campos de luta por direitos e deveres sociais. É uma disputa de saberes e interesses travada no campo político, permeada por aspectos sócio-culturais e econômicos. Neste sentido, o presente trabalho objetiva uma discussão conceitual sobre esse tema, desenvolvendo a concepção teórica sobre a análise de políticas, enquanto uma metodologia de estudo, compreendendo as categorias: atores, conteúdo, contexto e processo, onde, nessa última, se delimitam especificamente os processos de construção de agenda, formulação e implementação de uma política. Esse quadro teórico é desenvolvido centrando a temática da prevenção da Aids, contextualizada no cenário brasileiro, a partir da qual são elencados alguns entraves das políticas propostas, articulando-as às considerações de especialistas que buscam reorientar as intervenções públicas de prevenção à Aids. Palavras-chave Políticas públicas, Síndrome de Imunodeficiência Adquirida 
As políticas públicas são respostas a determinados problemas sociais, ${ }^{1}$ formadas a partir das demandas e tensões geradas na sociedade. Problemas que precisam ter magnitude e relevância social e que tenham poder de barganha suficiente para serem postos na agenda de prioridades de um determinado órgão fomentador de políticas, que pode ser ou não estatal.

Acredita-se que na formulação e implementação de uma determinada política pública entram em jogo questões tanto de ordem objetiva, relacionadas com equipamentos públicos, serviços, disputas políticas, locação de recursos, entre outros, quanto questões de ordem teórica, como concepções de sujeitos sociais, cidadania e inclusão social. Essas determinações encontram-se intimamente relacionadas, e juntas refletem o perfil da administração pública. ${ }^{2}$

Uma política pública pode ser regida por diretrizes que, em princípio, visem a garantia dos direitos sociais, mas durante seus processos de implementação, devido a diversos fatores, suas ações podem findar por serem contrárias às diretrizes iniciais e reforçarem, por exemplo, as desigualdades sócio-culturais, o que repercute diretamente na garantia dos direitos sociais. 3

Buscando pensar nessas questões, propõe-se analisar as políticas públicas, tendo-se como pano de fundo a prevenção do HIV/Aids. Isso porque, assim como a reforma sanitária brasileira, expressa no modelo do Sistema Único de Saúde (SUS), a política brasileira de prevenção da Aids assume lugar de destaque internacional, por refletir posicionamentos ideológicos inovadores em defesa dos direitos sociais, inclusões sociais, respeito e legitimação das diferenças, cidadania, entre outros. 4

\section{Políticas públicas: definindo conceitos}

O termo Políticas Públicas tem sido freqüentemente trabalhado no contexto de áreas e setores políticos específicos. Entretanto, é possível compreender políticas públicas enquanto conceito amplo e abrangente, desvinculando-o das diversas áreas a que pode ser aplicado, entendendo-as enquanto ações públicas que tentam regular problemas públicos, ou seja, problemas que surgem no bojo de uma sociedade e que têm relevância social.5

Entendemos as políticas públicas como sendo o conjunto de diretrizes e referências ético-legais adotados pelo Estado para fazer frente a um problema que a sociedade lhe apresenta. [...] é a resposta que o Estado oferece diante de uma necessidade vivida ou manifestada pela sociedade. (Teixeira, 1997, p. 43).5
Pode-se definir que as políticas são públicas porque têm interesses públicos e fins públicos, podendo ou não ser subsidiadas ou implementadas pelo poder estatal. Mesmo considerando o debate existente acerca do papel das organizações nãogovernamentais (ONGs) frente ao estado, quanto à sua função de controle social, é freqüente grupos sociais, a exemplo de ONGs, implementarem políticas públicas. ${ }^{6}$ Suas ações, contudo, devem ser reguladas pelo Estado e estar a serviço dos seus objetivos últimos, quanto ao bem estar coletivo.

As políticas públicas, mesmo buscando apaziguar as tensões, não conseguem eliminar o conflito social. Caso o fizessem, estariam, em última instância, predizendo uma sociedade utópica. O conflito existe, e dele se mantém a dinâmica social. Daí a relevância da contínua negociação de interesses dos diversos segmentos sociais, e conseqüentemente, do controle social e da participação e organização da sociedade civil.

Como argumenta Viana,1 a percepção do grau e da qualidade da regulação de um determinado problema, poderá ser distinta para diferentes atores sociais, a partir da interferência que esse problema assume sob suas vidas.

É imprescindível salientar que políticas públicas constituem-se num processo dinâmico onde interagem uma diversidade de atores e intenções, jogos de poder, recursos financeiros, estruturas políticas e sociais, entre outros, não sendo apenas resultado de definições, restritas ao campo político, e da execução dessas, restritas ao campo administrativo.7

São ações públicas que se encontram contextualizadas nos diferentes problemas que visam responder, ou seja, se estruturam a partir de uma realidade concreta. Retomando Texeira, (1997) 5 ao assumir uma demanda social, o Estado define sua área de atuação (por exemplo: saúde ou educação). A partir dessa, monta estratégias, mais ou menos estruturadas, desde ações pontuais até programas, delegando responsáveis e disponibilizando equipamentos, instrumentos e outros recursos.

Há várias formas de se analisar teoricamente as políticas públicas, estejam essas inseridas em qualquer área temática. $O$ presente trabalho segue a proposta de análise de políticas públicas de Araújo ${ }^{8}$ que caracteriza as mesmas como uma categoria de estudo, com metodologias próprias e que deve ser claramente definida, pois reflete uma forma específica de compreender as políticas públicas e seu estudo. 


\section{A análise das políticas públicas}

A "análise de política" é uma técnica de estudo que permite formar uma opinião acerca de determinada política pública. De acordo com os interesses e do ponto do qual se interpreta e analisa, podem-se obter diversos julgamentos sobre a mesma, possibilitando comparações com outras. ${ }^{8}$

Na perspectiva da "análise" são considerados os discursos oficiais e não oficiais, ou seja, os discursos explícitos e implícitos, considerando, inclusive, o estudo da ausência de uma política, já que o silêncio acerca de uma determinada questão pode ser uma estratégia de ação frente à mesma. ${ }^{8}$

Este referencial teórico amplia e facilita a observação de diversos determinantes, pois permite visualizar os diferentes elementos que estruturam a política (em todo o seu processo). Esses determinantes podem ser de ordem política, ideológica e social, ou ainda, determinações calcadas em interesses pessoais ou em evidências, sejam epidemiológicas, sociais ou econômicas. 9

A "análise" objetiva intervir nas políticas públicas, seja no sentido de formulá-las, ou propor outras diferentes, analisando-as antes, durante ou após sua implementação. O importante, salientam Araújo e Maciel,10 é que seja possível o fortalecimento teórico do campo e o desenvolvimento, e aprimoramento, no âmbito das intervenções públicas.

Definir o método de análise é imprescindível, pois permite que diferentes estudos possam ser comparados e replicados. Muitos métodos de análise não consideram a multiplicidade de fatores, atores e elementos que configuram a complexidade do evento processual, a partir do qual se caracteriza uma política pública. 7

Walt e Gilson ${ }^{11}$ propõem o uso de quatro categorias de análise: contexto, atores, conteúdo e processo. Por sua vez, Araújo e Maciel 10 vão além da proposição de seus antecessores, buscando definir "o quê" e "como" estudar cada uma dessas categorias. Entretanto, enquanto estes autores enfocam, preferencialmente, as produções socioeconômicas, no presente trabalho são consideradas, prioritariamente, as produções sócio-culturais, tendo como pano de fundo as políticas públicas de prevenção da Aids, desenvolvidas no Brasil.

Desta forma, as quatro categorias de análise definidas por Araújo e Maciel10 serão apresentadas sob um novo recorte interpretativo, sendo reorganizadas conceitualmente, ganhando as seguintes definições:

O contexto caracteriza o ambiente no qual a política é proposta e implementada. Esse se refere às produções sócio-históricas, políticas e ideológicas que circunscrevem a política e que dão sentido à mesma. Pode-se concluir, inclusive, que a política surge como resposta ao contexto, interferindo e sendo reformulada pelo mesmo. Isso implica em dizer que as políticas públicas são históricas e comprometidas com determinados contextos, seja com o objetivo de modificá-los, ou perpetuá-los.

Na perspectiva de Araújo, ${ }^{8}$ podem ser diferenciados o macro e o micro contextos; o primeiro representando a dimensão ampla e o segundo, a dimensão setorial da política em estudo.

No macro contexto várias características podem ser evidenciadas, considerando as diferentes esferas de análise:

$\mathrm{Na}$ esfera política: com a qual podem ser consideradas as mudanças de política, os regimes políticos em vigência, as ideologias dominantes, as políticas públicas propostas e as influências internacionais.

$\mathrm{Na}$ esfera econômica: podem ser consideradas as mudanças e condições da economia, as políticas econômicas e financeiras em execução e os gastos públicos existentes.

$\mathrm{Na}$ esfera social: podem ser consideradas as mudanças demográficas da região, a qualidade de vida e as condições de pobreza da população e a distribuição de renda e suas disparidades quando comparados os diversos segmentos sociais.

Para o estudo do microcontexto podem ser analisadas:

A política setorial: identificando seus principais interesses, os principais jogos de poder dentro do setor, as políticas públicas implementadas e a relação existente entre o setor público e privado.

As finanças do setor: analisando o orçamento e os gastos existentes dentro do setor, as políticas e mecanismos de financiamento, assim como as fontes de recursos.

Os problemas sociais e os serviços existentes: analisando, no caso, o setor saúde, podem ser consideradas as mudanças epidemiológicas, os principais problemas de saúde existentes, os recursos humanos disponíveis e a rede de serviços estruturada.

No campo das políticas públicas da Aids no Brasil, pode ser citado, como exemplo de macrocontexto, a implementação do modelo SUS, a política econômica atual e os principais indicadores socioeconômicos da população brasileira, que delineiam a conjuntura sócio-política e econômica do país, na qual a política de Aids é desenvolvida.

Como microcontexto, é possível compreender as políticas específicas no campo da Aids, como a atual 
proposição de redução de danos e de distribuição de preservativos; o papel dos movimentos sociais e do Banco Mundial na definição de políticas e os principais perfis epidemiológicos da Aids no país.

Isto porque, no Brasil, a política de Aids, seguindo a problematização sobre os grupos populacionais mais vulneráveis, impulsionou discussões cruciais tanto sobre populações usuárias de drogas (propondo uma nova modalidade de intervenção e de compreensão da problemática), quanto sobre a sexualidade dos sujeitos (identificando os serviços de saúde como um locus de debate sobre práticas sexuais), desmistificando o uso do preservativo. Essa política também está implicada com os financiamentos do Banco Mundial, que ditam diretrizes e metas, além de ter como ator estratégico para as definições de políticas os movimentos sociais, dentre eles os de populações marginalizadas, como os homossexuais. 12

Considerar tais elementos é de fundamental importância, pois contextualizam o fenômeno da Aids no Brasil, dando sentido às políticas públicas daí oriundas.

Para a análise da categoria conteúdo, Araújo8 propõe que sejam considerados os programas, projetos e ações desenvolvidos, buscando definir seus objetivos e metas. Ainda dentro dessa categoria de análise, devem ser considerados:

- Os resultados obtidos pela política, considerando o alcance ou não das metas propostas;

- A coerência entre os objetivos e metas propostos em relação aos programas, projetos e ações desenvolvidos;

- A perspectiva político-social que fundamenta as propostas da política (objetivos, metas, programas, projetos e ações).

Partindo de uma interpretação mais sóciocultural dessa categoria, é possível considerar como "conteúdo da política" todos os significados que a sustentam e que se expressam nos seus programas, projetos e nas mais diversas ações programáticas e produtos. Trata-se de compreender quais as ideologias, valores, crenças e representações que orientam a política, podendo assumir características neoliberais, social-democráticas, conservadoras, socialistas ou feministas.

Pode-se, atualmente, evidenciar que a política nacional de prevenção da AIDS tem fortes elementos, por exemplo, feministas. Essa política traz discussões a respeito das desigualdades nas relações de gênero para a discussão da vulnerabilidade e definição de estratégias e ações prioritárias, como a disponibilização do preservativo feminino. 13

Entretanto, encontram-se, nessa mesma política, outros determinantes que orientam, por exemplo, a prevenção da transmissão vertical, pelo Projeto Nascer, 14 que muitas vezes parece reduzir a mulher a sua condição reprodutora 15 e que contradiz uma proposta feminista de compreender a prevenção da Aids.

A política pode ser permeada por diversos conteúdos, por vezes até contraditórios, mas que se organizam de determinada forma a dar-lhe corpo e estrutura, não sendo muitas vezes possível definir um único perfil que a delimite.

$\mathrm{Na}$ categoria de análise "atores" devem ser consideradas todas as pessoas, instituições e organizações sociais que se relacionam direta ou indiretamente com a política, em todas as fases de seu processo. Araújo e Maciel10 propõe que sejam identificados os principais atores envolvidos com a política em estudo, em especial seus formuladores e implementadores.

Nessa categoria, devem ser analisadas, ainda, as posições de cada ator em relação à política e seu grau de mobilização, identificando seus os opositores e apoiadores.

Por fim, deve ser analisada a correlação de forças existente entre os diferentes atores considerados, identificando as alianças e confrontos conformados, assim como, os principais beneficiados e/ou prejudicados pela política.

No cenário da Aids há numa infinidade de atores envolvidos, entretanto, alguns movimentos sociais se destacam, como as feministas, os homossexuais e as organizações de pessoas que vivem com HIV/Aids. 16 Outra característica marcante dos atores no cenários da Aids é que esses pertencem, ao mesmo tempo, a vários grupos que têm diferentes implicações com a política, pois muitos militantes sociais também se encontram nas universidades, ou mesmo como gestores e implementadores das políticas. 17

Por fim, a categoria de análise-processo. As políticas públicas são processuais, dinâmicas e dialéticas, não sendo possível separar cada uma de suas fases, a não ser para fins didáticos. Para vários autores, inclusive Walt e Gilson, 11 essas fases ou etapas se resumem na identificação de problemas, formulação da política, implementação e avaliação.

Para Araújo, 8 são especialmente relevantes os momentos de formulação e implementação da política, devendo ser identificados, dentre outros, os seguintes aspectos:

- O processo de tomada de decisão, identificando se o poder decisório é restrito a uma elite de atores ou compartilhado com diversos outros;

- A extensão da política, identificando em que 
medida ela afeta as estruturas maiores da sociedade e implica em significativas somas de recursos;

- O tipo da política, ou seja, se ela redistribui os recursos disponíveis, presta serviços ou disponibiliza bens de consumo, sem reduzir benefícios de uns, em detrimento de outros, e se estabelece regras definidas pelo poder público sobre interesses privados ou apenas sobre interesses públicos;

- A forma de implementação, analisando se os gestores de primeiro escalão têm o poder decisório e os demais são vistos como "meros" implementadores ou se os implementadores da política são convocados a pensar e decidir sobre a mesma.

Uma vez que o presente estudo tem como proposta centrar menos atenção às questões políticoeconômicas e dar maior relevância aos aspectos sócio-culturais das políticas, é possível, junto a essas definições, considerar, ainda, as contribuições de Viana,7 que definem a produção de uma política pública a partir de quatro momentos, não necessariamente cronológicos: construção da agenda, formulação, implementação e avaliação.

\section{A construção de uma agenda}

Na construção da agenda são estabelecidas as prioridades, definindo-se as ações de rotina e as estratégicas. Nessa definição entram em jogo diversos elementos, desde recursos até pressões sociais.

Para a compreensão da dinâmica na construção de uma agenda, há três pontos importantes a salientar: o primeiro diz respeito à disputa decisória, onde fatores mais ou menos relevantes ganham força de acordo com o interesse dos fazedores da política (interesses pessoais ou de grupos sociais). A segunda questão diz respeito ao espaço político e temporal de uma gestão e a terceira, à participação social e à democracia.

Com o fortalecimento do saber epidemiológico e da perspectiva sanitária, cresce a tendência de fundamentar a política em evidências, 18 o que eleva à implicação dos indicadores epidemiológicos no processo de definição de agenda. No caso da política pública de prevenção da Aids, os dados epidemiológicos são de fundamental importância, pois evidenciam a magnitude do problema. O Brasil acumulou de 1980 até junho de 2004 um total de 362.364 casos de Aids. ${ }^{19}$ Esse dado precisa ser considerado com cautela visto que, além de ser resultado de uma notificação historicamente frágil no Brasil, para a grande maioria dos agravos, não contabiliza os sujeitos soropositivos, nem oferecem estimativa do potencial de disseminação do vírus HIV, o que sugere que a magnitude da problemática seja bem mais elevada do que a apresentada.

O cuidado com a cautelosa utilização dos recortes epidemiológicos também se deve ao fato de que os mesmos orientam estratégias e ações programáticas, especificando populações e regiões que apresentam risco acrescido. Esses recortes favoreceram em muitos momentos a segmentação da Aids enquanto fenômeno social e a estigmatização de grupos sociais. Apoiada em dados epidemiológicos, a Aids foi referida por muito tempo como a "peste gay" sendo compreendida como uma doença fatal, reflexo de práticas sociais desviantes, de acordo com códigos morais e religiosos hegemônicos. 20

Por outro lado, sabe-se que um fenômeno, apenas por se caracterizar em termos epidemiológicos como um problema de saúde pública, não garante sua indicação como prioridade na agenda. Tem-se, como exemplo, a hepatite C, que atualmente é considerada uma grave pandemia, 21 mas que não é alvo de uma política pública de prevenção da magnitude da política de Aids. Isso porque, outros elementos entram em questão, como, por exemplo, o poder de pressão dos movimentos sociais organizados e interesses políticos e econômicos.

No caso da Aids, os movimentos sociais encontram-se fortemente estruturados e com maciça representatividade em diversos espaços de controle e pressão social, o que pode ser evidenciado em vários momentos da história de luta deste segmento no Brasil e no Mundo, como, por exemplo, sua inegável contribuição na luta pela patente dos medicamentos ou, pela distribuição dos mesmos. 17,22

O movimento feminista teve lugar de destaque com seu protagonismo social e político para a construção do conceito de promoção da saúde, estando presente em grande parte dos documentos e declarações internacionais sobre o tema. 23 Também foi a partir das contribuições feministas que se desenvolveu o conceito de "empoderamento" com o qual foi proposta uma perspectiva crítica positiva dos conceitos e práticas relacionadas à noção de comportamento de risco. 24

Ainda como atores sociais importantes para as negociações na priorização de temas na agenda política, pode-se considerar os acadêmicos, pesquisadores e consultores, além da mídia, partidos políticos e a opinião pública. ${ }^{16}$ Deve-se, contudo, lembrar que esses grupos muitas vezes se entrelaçam, havendo muitos consultores, pesquisadores e acadêmicos dentro dos partidos políticos, nos movimentos sociais e com acesso à mídia, sendo impor- 
tantes formuladores de opinião pública.

Por fim, pode-se ainda salientar como importante elemento que coloca a Aids como uma problemática prioritária na agenda das diversas esferas do poder público, a pressão política e o incentivo financeiro internacional. Considerada, nas últimas décadas como a prima rica da saúde, a Aids vem se destacando na agenda política pelo volume de recurso que disponibiliza e que tem como principal financiador o Banco Mundial.25

O Banco Mundial tem uma atuação tão expressiva na definição das políticas públicas referentes à Aids que possibilitaria a realização de um estudo específico. Não apenas no Brasil, mas em todo o mundo, esse tem financiado diversas intervenções e imprimido suas diretrizes e prerrogativas, que são mais ou menos implementadas pelos diversos estados nações de acordo com seus contextos sóciopolíticos. 26

Os recursos destinados a uma determinada política podem favorecer outras tantas que estejam imbricadas, como no caso da Aids, onde seu financiamento se articula com políticas de saúde da mulher, saúde da criança e do adolescente, saúde do trabalhador e outras. Trata-se de um financiamento que por ser grande e articulado com diversas questões, torna a política da Aids extremamente estratégica e vendável. Pode-se compreender esta relação, por exemplo, quando tanto a política de planejamento familiar, quanto à de prevenção das DST e Aids implicam na distribuição de preservativos. Tais programas visam, em última instância, um mesmo objetivo, a saber, o aumento da utilização de preservativos, seja para evitar a gravidez não planejada, seja para a prevenção de DST e Aids. Entretanto, sabe-se que os recursos para a compra de preservativos, ou mesmo o repasse desse insumo do nível nacional para os municípios são bem mais significativos no âmbito da política de DST e Aids do que da saúde da mulher, setor responsável pelo planejamento familiar. Assim, o planejamento familiar ganha força com o aumento do acesso a um insumo estratégico, a partir de sua correlação com a política de Aids.

Contudo, como afirma Parker27 o recurso do Banco Mundial, previsto para o Projeto Aids é finito. Isso implica que a continuidade das ações da Aids dependerá da disponibilização dos recursos do Tesouro Nacional, passando a concorrer com as demais políticas existentes. Por isso, a grande preocupação do programa nacional de DST e Aids e das principais fontes financiadoras tem sido propor a sustentabilidade da política. 28
Ao referir o conceito sustentabilidade é importante considerar que se trata não somente das fontes de recursos físicos, humanos e financeiros para execução de políticas e ações em saúde. Sustentar significa dar o apoio, a base, o suporte fundamental para o re-ordenamento desses recursos tão necessários. A sustentação das políticas públicas de saúde significa assegurá-las como prioridade, significa reconhecê-las como uma estrutura com elementos inalienáveis e, por fim, significa defendê-las dos movimentos de fragmentação e desmobilização destes elementos. A partir disso é que são geradas condições viáveis para a constituição dos seus recursos (Ávila, 2001, p. 32.28

A viabilidade financeira é um importante fator que define a política a ser desenvolvida, que pode, inclusive, interferir nas concepções teóricas que lhe dão suporte.

Os entraves financeiros salientam a discussão das propostas de intervenção, na medida em que se buscam ações que assumam sistematicidade e continuidade e que não se atrelem a recursos externos ou prazos pré-estabelecidos em projetos e financiamentos.

Esta relevância se torna evidente inclusive porque, é necessário que os trabalhos destinados à prevenção sejam garantidos, independentemente do caminhar da epidemia, uma vez que esses, quando bem orientados, podem trazer ao debate a construção de sujeitos com autonomia frente a sua sexualidade, assumindo sua identidade sexual, construindo novos valores e novas possibilidades de obtenção de prazer, no exercício da cidadania. 29

Se um dia chegar a cura da Aids que tanto esperamos, que esta experiência permaneça como inspiração para os que vão continuar enfrentando a falta de direitos sexuais e de acesso à saúde reprodutiva que, infelizmente, num país tão desigual como o nosso, teimarão no tempo (Parker, 1997, p. 25).27

Entretanto, a manutenção ou proposição de uma política nem sempre se dá a partir do que pesquisadores evidenciam como relevantes para o desenvolvimento da qualidade de vida de uma população. Por esse motivo, há, atualmente, a proposição de se fazer política baseada em evidências, que busca fazer frente à pouca importância dada a evidências concretas, estudos de relevância e impacto de uma determinada política, no momento de se optar pela mesma. ${ }^{9}$ Como aponta Viana, ${ }^{7}$ grande parte das políticas públicas é desenvolvida a partir de preferências, predileções, orientações e expectativas dos formuladores das políticas. Ou seja, 
grande parte do tempo, é o governo executivo que, a partir de suas próprias convicções e interesses, determina a agenda política.

Por outro lado, a pressão social é um forte elemento na definição da agenda política, que vai estar intrinsecamente relacionada com o caráter mais ou menos democrático da gestão pública e com a capacidade de organização popular. Deve-se salientar que no campo da democracia é dever do Estado fomentar a organização e o controle social, o que no setor saúde foi fortalecido com a Lei 8.142 que dispõe sobre a participação da comunidade na gestão do SUS, dentre outras providências, como a legitimação das conferências e dos conselhos de saúde em cada esfera de governo. ${ }^{30}$

A fragilidade da participação popular nas definições políticas abre espaço para o poder executivo definir, a partir dos seus interesses, a agenda política.18 É nesse cenário que os interesses hegemônicos se fortalecem, inclusive no âmbito da Aids, e mantém estruturas tradicionais de se pensar e fazer política pública.

Foi exatamente buscando romper o poder hegemônico que os movimentos sociais marcaram sua expressiva presença no cenário da Aids. A luta dos homossexuais em romper com o esteriótipo do "câncer gay", representação social construída acerca da Aids na década de 1980,31 possibilitou não apensas um outro olhar sobre essa população, como redefiniu as noções de risco e de cuidado.

Pode-se questionar, ainda, em que medida houve mudanças na formulação das políticas de Aids a partir do momento em que essa passa a atingir, de forma significativa, segmentos não marginalizados da sociedade, como no caso de mulheres, heterossexuais, donas de casa; o que aumentou, conseqüentemente, a incidência do HIV em crianças, via transmissão vertical. 15

Uma vez atingindo as mulheres e homens que se enquadravam no perfil de heterossexuais, casados e não usuárias de drogas, a Aids ganha nova cara, assim como sua política de prevenção. Refaz-se a representação social da Aids como doença de pessoas que desenvolvem práticas sexuais perversas e a política de prevenção centra-se no uso indiscriminado do preservativo, 32 ao contrário da anterior preocupação dirigida apenas às populações marginalizadas.

Apesar de toda construção simbólica desenvolvida sobre vulnerabilidade e risco, no contexto da Aids e das identidades sexuais, ainda persistem crenças e valores ideológicos que fundamentam políticas públicas como a do "Abstinence; to $\mathrm{Be}$ monogamous; Condom"(ABC), que ao ser finan- ciada pelo Banco Mundial tem larga disseminação em todo o mundo. A política em questão propõe a abstinência sexual ou o retardo da primeira relação sexual ao máximo; a redução de parceiros, calcada na monogamia e na heterossexualidade e finalmente, no uso de preservativo, dentro dessas condições. ${ }^{29}$ A referida política aparece como uma clara contradição frente ao que vem sendo discutido pelos autores citados ao longo deste trabalho 24,25,29 acerca das estratégias de prevenção que considerem a legitimação das diversas experiências sexuais e identitárias dos sujeitos, garantindo-lhes o direito de cidadania e inclusão social. Mesmo assim, por ter como financiador uma instituição do porte do Banco Mundial, essa política tem ganho cada vez maior expressão no cenário mundial, o que evidencia a relevância dos fatores políticos e econômicos para a definição das políticas públicas.

Uma vez tendo sido elencados vários dos fatores que permeiam a construção de uma agenda política, é possível centrar a discussão na etapa de formulação, focando os diversos elementos que interferem no mesmo, compreendendo que, na prática, esse ocorre não apenas articulado com a construção da agenda, mas em paralelo à mesma, muitas vezes reformulando-a.

\section{A formulação de uma política}

Pode-se considerar que a formulação da política é aquele momento em que se pensa e define o que será realizado. É um processo teórico, no qual não deixam de estar atrelados interesses políticos, pressão de grupos sociais, disponibilidade de recursos e a própria experiência dos gestores.

A política em si caracteriza-se como o diálogo entre sua formulação e sua implementação, ou seja, a interação entre o que se propõe executar e o que se realmente executa. Desse diálogo deve surgir a constante avaliação e monitoramento das ações e formulações e reformulações constantes da política. É esse movimento que caracteriza a dinamicidade do processo de construção das políticas públicas e que se amplia a própria concepção de formulação, implantação e avaliação, não mais como momentos estáticos e independentes, mas como partes de um processo contínuo de construção e reconstrução. Nesse sentido, o planejamento das ações, que a priori poderia ser pensado como parte do processo de formulação da política, ganha nova conotação, adquirindo a característica de processo.

Isto implica, por exemplo, que mesmo sendo formulado um Plano Pluri-Anual (PPA), é preciso 
que anualmente seja feito novo planejamento das ações, avaliando o que já foi realizado e o que há para ser implementado. Essa avaliação deve ser feita considerando a realidade atual, que é dinâmica e mutável, constituindo novas conjunturas e necessidades que interferem diretamente no que se propõe realizar.

Ayres et al. ${ }^{24}$ defendem que nas formulações de políticas é imprescindível que sejam analisadas as reais possibilidades dessas serem postas em prática. Isso requer que sejam consideradas as chances dessa política, ou mesmo de ações programáticas específicas, serem efetivadas, ou seja, se o objetivo que se deseja alcançar será realmente possível, a partir da realidade política, filosófica, ética e técnica, na qual se trabalha. Implica, ainda, em considerar se os recursos disponíveis, materiais ou simbólicos, permitem a operacionalização da ação/política, e na necessidade de avaliar se sua implantação requer medidas de curto, médio ou longo prazo, com o objetivo de planejar e monitorar o que se propõe viabilizar.

Viana ${ }^{7}$ propõe que a formulação da política se estruture nos seguintes processos: percepção da necessidade (o qual poderia ser entendido como definição de necessidades negociadas), elaboração de um plano preliminar, equacionamento do problema do financiamento (ou adequação do desejado ao possível ou negociado financeiramente), plano detalhado, aprovação institucional, implementação e feedback. Ou seja, trata-se, como propõem Araújo e Maciel,10 de definir estrategicamente como se colocará em prática a política, com planejamento e pactuação, considerando a realidade, os atores implicados, os insumos disponíveis, as intervenções necessárias e as metas desejadas.

A partir da formulação da política, processo que se estrutura em negociações de diferentes ordens, tem-se o processo de implementação da mesma. Pode-se dizer que esta fase caracteriza-se como o "por a política em ação". Trata-se da própria execução-ação do que é pensado e negociado.

\section{A implementação da política}

Evidentemente, como já salientado, no processo de implementação também ocorrem disputas, pressão social, interesses individuais dos atores envolvidos, interferências por falta de recursos, entre outros, a partir dos quais são redefinidas prioridades, metas e ações.

Para a implementação de uma política é necessário que haja um bom planejamento, com metas e ações bem delimitadas e com definição de prazos, atores responsáveis e recursos necessários.

É preciso ainda adequação das ações às conjunturas sócio-políticas e econômicas, e a constante negociação com a população para a qual a ação é pensada, que tem seus próprios interesses, orientados seja por convicções políticas e ideológicas, seja por manobras de grupos hegemônicos ou interesses particulares.

Propõe-se, neste momento, a partir de duas estratégias políticas de prevenção da Aids, evidenciar como a implementação de política pública de saúde pode assumir diferentes contornos que podem respeitar ou não os direitos dos cidadãos.

Como primeiro exemplo, pode-se discutir a estratégia de distribuição de preservativos. Na Política Nacional de DST e Aids 33 a distribuição de preservativos é uma ação prioritária quando se pensa a prevenção.

As campanhas publicitárias têm especial relevância neste contexto, na medida em que massificam informações, transmitindo concepções de risco e prevenção que sustentam as políticas desenvolvidas. Elas reforçam a necessidade do uso do preservativo, muitas vezes, inclusive, numa linguagem diretiva e normatizadora: "Use camisinha!". A "camisinha" é coroada como a mais importante forma de prevenção, simples e possível de ser adquirida nos postos de saúde.

Os cidadãos teriam, assim, todas as condições de se prevenirem, sendo desconsideradas questões outras de ordem tanto subjetiva, quanto sóciopolíticas, que interferem em suas negociações para o uso do preservativo. Essa lógica deu suporte para slogans como o da campanha do Ministério da Saúde, em 1999 - "Viver sem Aids só depende de você", que pressupõe a responsabilização e culpabilização do sujeito infectado por sua condição, que teoricamente teria todas as condições de se prevenir e não o fez.

Tal concepção interfere claramente na forma do sujeito soropositivo se reconhecer e ser reconhecido no social, o que tem implicações diretas em sua sociabilidade, inserção social e luta por seus direitos.

Não é possível pensar no incentivo à utilização de preservativos como uma estratégia de política pública de prevenção eficaz, sem considerar aspectos políticos e econômicos que interferem na quantidade de preservativos disponibilizados na rede, uma vez que a compra desse insumo implica em significativo investimento financeiro e conseqüentemente deliberações e comprometimento políticos de diversas ordens e instâncias. É imprescindível a disponibilização de um quantitativo que 
dê conta de toda a demanda populacional, inclusive de grupos específicos como profissionais do sexo, já que parece ser inviável se pensar que populações de baixa renda priorizem a compra de preservativos em detrimento de alimentos ou medicamentos, por exemplo.

Entretanto, pode-se, ainda, considerar alguns fatores de ordem cultural que interferem na distribuição de preservativos e que muitas vezes impedem a prática preventiva dos sujeitos, mesmo dos que poderiam ter acesso ao referido insumo.

São relevantes questões como o posicionamento dos profissionais dos serviços de saúde frente aos cidadãos que buscam preservativos. Uma vez que as DST e Aids são culturalmente atreladas à promiscuidade ou atividades sexuais infiéis ou marginalizadas, 32 o uso do preservativo é muitas vezes atrelado a populações estigmatizadas. Muitos sujeitos que buscam os serviços de saúde para receber preservativos são questionados sobre sua sexualidade, sendo freqüentemente a distribuição desse insumo atrelada à participação de palestras sobre sexualidade que muitas vezes podem reforçar rotulações, normas estandartizadas.

Ao mesmo tempo, na medida em que se mantém esta construção cultural associando a "camisinha" a práticas sexuais marginalizadas, contribui-se para certas noções de risco que inviabilizam, por exemplo, que homens e mulheres casados permitam o uso da "camisinha" em suas relações conjugais. 32

Propor o uso do preservativo implica, neste sentido, em ações que se aproximem da realidade populacional, reconhecendo e legitimando as diferenças culturais, para, a partir delas, buscar formas de se fazer prevenção.

Considerar a realidade do sujeito a que se destina a política é relevante não apenas por uma questão técnica, que viabiliza uma melhor adequação da intervenção e, conseqüentemente, maiores êxitos, mas representa, antes de tudo, uma responsabilidade ética do gestor frente à população para a qual trabalha.

Essa relevância é possível também ser observada, ainda, num segundo exemplo de estratégia política de prevenção em Aids que pode, dependendo da forma de sua efetivação, garantir ou não os direitos dos cidadãos e que diz respeito à disponibilização do teste sorológico para o HIV.

É recomendação da Política Nacional de DST e Aids $^{33}$ que seja disponibilizada em toda a rede de saúde essa testagem. Entretanto, seu oferecimento pode ser muitas vezes transformado em imposição, dependendo da forma que seja trabalhado. Deve-se questionar se o teste é realmente disponibilizado para todos ou se na prática há um incentivo quase impositivo para sujeitos pertencentes a grupos marginais.

Submeter-se a um teste de para a detecção da infecção pelo HIV nem sempre é fácil. Uma vez que a AIDS foi socialmente construída a partir de noções de morte, promiscuidade e grupos marginais, a realização do teste representa a possibilidade do sujeito atrelar-se a esses conceitos. O medo da morte e de ser reportado aos grupos estigmatizados provoca hesitação em muitos que se propõem fazê-lo.

A realização do teste deve ser uma escolha do próprio sujeito, não podendo se tornar uma imposição da sociedade. Sua obrigatoriedade transforma-o num instrumento de exclusão e apartação social. As diferenciações sociais não devem perpassar pelas diferenças de sorologia para o HIV. Cada um tem o direito legal, que deve ser legitimado socialmente, de desejar, ou não, saber sobre sua condição sorológica. Ela deve ser investigada para o cuidado com a saúde, sem correr o rico de se transformar numa estratégia de exclusão entre os sujeitos.

Ao mesmo tempo, a realização do teste coloca em questão o direito de sigilo do sujeito sobre sua sorologia, o que não pode ser considerado uma ameaça aos que o cercam. Ele deve ser compreendido enquanto um direito, legalmente assegurado, de o sujeito não ser publicamente exposto a situações de constrangimento.

A estratégia política para a prevenção do HIV/Aids, a partir do incentivo do teste, implica na estruturação de uma rede que possa garantir o efetivo acesso da população à testagem, o direito do sujeito desejar ou não se submeter ao teste, trabalhos de aconselhamento pré e pós-teste, sistema de referência e contra referência, além do sigilo do resultado. Sem tais garantias, a oferta do teste pode não apenas tornar-se sem efeito, como mais gravemente, ter sérias repercussões como a desintegração do sujeito no seu meio social.

Muitas vezes, apenas ouvindo as populações a quem se destinam as políticas públicas, torna-se possível visualizar tais implicações éticas. Por isso, é imprescindível a construção coletiva da política, que além de implicar em democracia e cidadania, possibilite a constante negociação de visões de mundo e concepções de saúde.

Não raramente, a população "alvo" da política tem uma concepção de melhoria de qualidade de vida diferente da perspectiva dos formuladores da política. Muitas vezes, sujeitos portadores de tuberculose não desejam o tratamento; pessoas mantêm focos de água parada, correndo risco de gerar criadouros de vetores da dengue; populações 
moradoras em áreas de risco optam por não mudar o local de residência; e usuários de drogas desejam a continuidade do uso das mesmas. Por questões ideológicas, falta de informação ou outros aspectos de ordem socioeconômica, religiosa ou cultural, muitas vezes é necessária a negociação entre o profissional de saúde que executa a ação programática e a população com a qual trabalha. ${ }^{34}$ Essa negociação permite aos sujeitos se expressarem e decidirem que tipo de vida desejam ter.

Neste campo do diálogo se estabelecem relações de direito mútuo, cidadania e respeito pelo outro, onde a saúde deixa de ser questão de controle para ser construção negociada de modos de vida satisfatórios para quem os vive. Trata-se, assim, de se construir uma intervenção sustentável, na medida em que, possibilitando a apropriação das noções de cuidado consigo e com o outro, os sujeitos podem desenvolver diversas e inusitadas formas de promover saúde.

Isso ocorre porque os sujeitos "alvo" da política deixam de ser passivos e passam a se apropriarem do processo de construção da saúde, avaliando, inclusive, a qualidade das ações desenvolvidas pelos implementadores da política.

Muitos autores já apontaram para a desconexão existente entre o saber dos formuladores e dos implementadores das políticas, como uma das principais dificuldades enfrentadas. 1 As políticas são formuladas por profissionais que têm conhecimentos teóricos e compreendem a problemática em tela, diferentemente dos atores que de fato as implementam. Essa descontinuidade é acarretada por diversos fatores, dentre os quais se pode citar o próprio conceito de construção de políticas. Isso porque ao se compreender o processo de construção da política como algo dinâmico, as fases de formulação e implementação se interrelacionam de tal forma que sua separação só pode ser aceita para fins didáticos.

Compreendendo-se essa dinamicidade, não há como se pensar numa política onde alguns atores sociais participem da formulação e outros da implementação. Na prática, tal dicotomia, bastante frequiente, aponta para uma forma de fazer política fragmentada, centralizada, não democrática e conseqüentemente, pouco eficaz.

No campo da prevenção da Aids, muitas vezes pode-se encontrar proposições teóricas que preconizam o debate sobre a sexualidade e a pluralidade das diversas orientações sexuais. Entretanto, tais conceitos, por não serem trabalhados anteriormente com os profissionais da ponta, podem levar a normatizações de condutas. Se os profissionais compartilham representações e valores sobre sexua- lidade a partir do referencial heterossexual e monogâmico, os mesmos poderão compreender que as práticas sexuais homossexuais e/ou poligâmicas da população a que assistem devem ser reorientadas, normatizadas ou corrigidas, a fim de ajudá-los a se protegerem do vírus HIV. Assim, se os formuladores da política não compartilham com os implementadores os valores, crenças, metodologias e objetivos da política que propõem, essa pode estar fadada a não obter os resultados esperados, não por uma incapacidade dos implementadores, mas sim por uma divergência, não explicitada e muito menos trabalhada, entre os diversos atores, acerca dos conteúdos que fundamentam a política.

Para que uma política seja implementada é imprescindível que seus realizadores estejam conscientes das metas e objetivos da mesma, que tenham uma postura crítica frente ao problema em questão e que compreendam e acreditem na importância de suas ações para o alcance do resultado esperado. Ou seja, é importante que os implementadores sejam sujeitos ativos no processo, conscientes de suas ações. Para tanto, é fundamental que não haja um limite entre os implementadores e formuladores da política, mesmo compreendendo que alguns atores que participam da sua formulação podem não ser seus implementadores, como no caso de teóricos, acadêmicos, gestores e os próprios usuários da política e a sociedade civil organizada.

Em situação diversa, mas bastante freqüente, os gestores se colocam de forma centralizada na formulação da política, compreendendo que basta apenas o repasse de informações para seus subordinados, os profissionais da ponta, os reais implementadores da política. Da mesma forma, estes mesmos profissionais, que não foram ouvidos na formulação, tornam-se os responsáveis pela ineficiência na implementação, servindo de bodes expiatórios, responsabilizados pelo não êxito de uma política que sequer pensaram, compreenderam ou mesmo concordaram. Trata-se de uma visão centralizadora, onde a ação do profissional deve ser regida não por suas crenças e valores, mas por um saber de fora, estranho, não compartilhado.

O mesmo ocorre com a população a que se destina a política, que assume o mero lugar de alvo da mesma, sendo-lhe impostas normatizações de condutas que lhe são estranhas e, por vezes, vendose responsabilizada pela eventual falência da política. 35 Esse fato é bastante claro quando se pensa em políticas de prevenção da Aids calcadas em normatização de condutas, 35 como por exemplo o uso do preservativo, sem que se leve em consideração que nem sempre essa prática é viável à população "alvo", 
tornando-se a referida população a única responsável por sua condição de risco frente ao HIV. A normatização, no final, busca a conformidade da população, que deve apenas seguir o que é preconizado pelos detentores do saber técnico-teórico.

Encarar o sujeito ao qual se destina a política como um mero receptor fornece à política um caráter pouco democrático e muitas vezes ineficiente. Para Ayres, 35 apenas dialogando com os sujeitos, compreendendo suas necessidades, possibilidades e vulnerabilidades é que se torna possível construir estratégias de intervenção que tenham maior grau de efetividade, pois tenderão a ser pactuadas, coletivamente protegidas e, conseqüentemente, com maiores possibilidades de serem estruturadas.

\section{Conclusões}

A análise de políticas públicas é um importante instrumento de gestão que permite compreender, por exemplo, como uma política pública de prevenção em Aids pode teoricamente priorizar a equidade e a universalidade dos serviços, assegurando a defesa das minorias e a legitimação das diferenças sociais e sexuais, mas ser marcada, em sua prática, por ações que intensificam a discriminação social, reforçam a marginalização e a exclusão social de certos grupos sociais, inviabilizando, inclusive, o acesso dos mesmos aos serviços de saúde oferecidos. 27

Pensar políticas públicas de prevenção da Aids implica numa leitura ampla de vários fatores sócio- político-econômicos e culturais que se fazem presentes e que delimitam as ações. Isso porque a implantação de tal política requer responsabilidade sanitária, recursos financeiros, capacitação de técnicos, organização do sistema de saúde, entre outras questões que evidenciam a complexidade não apenas da temática Aids, como também das políticas públicas de saúde.

A análise de política possibilita compreender o processo no qual essa é proposta, seus objetivos, metas, além de possibilitar a visualização crítica acerca dos interesses e jogos de poder nela implicados. A partir dessa proposição teórica pode-se desenhar a concepção e implantação da política, permitindo, não apenas a explicitação de determinantes invisibilizados, mas ainda a pontuação de alguns estrangulamentos e dificuldades, contribuindo significativamente para a reformulação de novas intervenções.

Este estudo buscou explicitar a relevância dos fatores sócio-culturais e subjetivos na implementação de políticas públicas, apresentando, assim, sua contribuição, na medida em que amplia o leque de discussão sobre as políticas públicas e conseqüentemente sobre a garantia dos direitos sociais. Com este trabalho, busca-se fazer pontes teóricas sobre os fatores objetivos e subjetivos que implicam na organização social, propondo a interface entre o econômico e o cultural, o político e o social, o objetivo e o simbólico, no bojo das análises das políticas públicas de prevenção em Aids.

\section{Referências}

1. Viana AL. Enfoques metodológicos em políticas públicas: novos referenciais para estudos sobre políticas sociais. In: Canesqui AM, organizador. Ciências sociais e saúde. São Paulo: Hucitec; 1997. Cap. 10, p. 205-15.

2. Contrandriopoulos AP, Champagne F, Denis J, Pineault R. A avaliação na área de saúde: conceitos e métodos. In: Hartz ZMA, organizador. Avaliação em saúde: dos modelos conceituais à prática na análise da implementação de programas. Rio de Janeiro: FIOCRUZ; 1997. p. 29-47.

3. Foltz AM. The policy process. In: Janosvsky K, editor. Health policy and systems development: an agenda for research. Geneva: WHO; 1996. p. 207-26.

4. Paiva V, Lima TN, Santos N, Ventura-Filipe E, Segurado A. Sem direito de amar? A vontade de ter filhos entre homens (e mulheres) vivendo com o HIV. Psicologia USP. 2002; 13: 105-133.

5. Texeira PR. Políticas públicas em AIDS. In: Parker R, organizador. Políticas, instituições e Aids: enfrentando a epidemia no Brasil. Rio de Janeiro: Associação Brasileira Interdisciplinar de AIDS; 1997. p. 43-68.
6. Farias MSQ, Dimenstein M. Configurações do ativismo anti-Aids: na contemporaneidade. Psicol Est. 2006, 11: 165-74.

7. Viana AL. Abordagens metodológicas e políticas públicas. Rev Adm Pública 1996; 2: 5-43.

8. Araújo JLJ. Health sector reform in Brazil, 1995-1998. An health politic analysis of a developing health system $[\mathrm{PhD}$ thesis]. Leeds: Course in Health Service Studies, The Nuffield Institute for Health, University of Leeds, 2000.

9. Barreto M. O conhecimento científico e tecnológico como evidência para políticas e atividades regulatórias em saúde. Ciênc Saúde Coletiva. 2004; 9: 329-38.

10. Araújo JLJ, Maciel RF. Developing an operational framework for policy analysis. Rev Bras Saúde Matern Infant. 2001; 1: 203-21.

11. Walt G, Gilson L. Reforming the health sector in developing countries: the central role of policy analysis. Health Policy Planning. 1994; 9: 353-70. 
12. Parker R. Construindo os alicerces para a resposta ao HIV/Aids no Brasil: o desenvolvimento de políticas sobre o HIV/AIDS, 1982-1996. Divul Saúde Debate. 2003, 27: 849.

13. Ministério da Saúde. Coordenação Nacional, DST e Aids. Políticas e diretrizes de prevenção das DST/Aids entre mulheres. Brasília (DF); 2003.

14. Ministério da Saúde. Programa Nacional de DST e Aids. Projeto Nascer. Brasília (DF); 2003.

15. Cavalcante M, Ramos Junior A, Silva T, Pontes L. Transmissão vertical do HIV em Fortaleza: revelando a situação epidemiológica em uma capital do Nordeste. Rev Bras Ginecol Obstetr. 2004; 26: 131-8.

16. Galvão J. A AIDS na mídia: da cura ao mercado. In: Comissão de Cidadania e Reprodução, organizadora. Olhar sobre a mídia. Belo Horizonte: Mazza; 2002. p. 77-107

17. Parker R. Na contramão da Aids: sexualidade, intervenção, política. Rio de Janeiro: Associação Brasileira Interdisciplinar de AIDS; 2000.

18. Pellegrine AF. Pesquisa em saúde, política de saúde e eqüidade na América Latina. Ciênc Saúde Coletiva. 2004; 9: 339-50.

19. Ministério da Saúde. Secretaria de Vigilância em Saúde Programa Nacional de DST e Aids. Bol Epidemiológico AID. Brasília (DF); 2004.

20. Pereira CAM. O impacto da Aids, a afirmação da cultura gay e a emergência do debate em torno do masculino - fim da homossexualidade? In: Rios LF, Almeida V, Parker R, Pimenta C, Terto JV, organizadores. Homossexualidade: produção cultural, cidadania e saúde. Rio de Janeiro: Associação Brasileira Interdisciplinar de AIDS; 2004. p. 52-62.

21. Passos A. Hepatite C: aspectos críticos de uma epidemia silenciosa. Cad Saúde Pública. 2006; 22: 1764-5.

22. Ramos S. O papel das ONGs na construção de políticas de saúde: a Aids, a saúde da mulher e a saúde mental. Ciênc Saúde Coletiva. 2004; 9: 1067-78.

23. Buss PM. Uma introdução ao conceito de promoção da saúde. In. Czeresnia D, Freitas CM, organizadores. Promoção da saúde: conceitos, reflexões, tendências. Rio de Janeiro: FIORCRUZ; 2003. p. 15-38.

24. Ayres JRCM, França Jr I, Calazans GJ, Saletti Filho HC. O conceito de vulnerabilidade e as práticas de saúde: novas perspectivas e desafios. In: Czeresnia D, Freitas CM, organizadores. Promoção da saúde: conceitos, reflexões, tendências. Rio de Janeiro: FIOCRUZ; 2003. p. 117-39.
25. Arilha M. Políticas públicas de saúde, mulheres e DSTs/Aids: reajustando o olhar. Rio de Janeiro: Associação Brasileira Interdisciplinar de Aids; 2001. (Coleção Associação Brasileira Interdisciplinar de Aids. Saúde Sexual e Reprodutiva, n. ${ }^{\circ}$ ).

26. Mattos RA, Parker R. As estratégias do Banco Mundial e a resposta à AIDS no Brasil. Rio de Janeiro: Associação Brasileira Interdisciplinar de Aids; 2001. (Coleção Associação Brasileira Interdisciplinar de AIDS. Políticas Públicas, n. $\left.{ }^{\circ} 1\right)$.

27. Parker R. Desafios para o futuro: questões-chave para a política de HIV/AIDS no Brasil. In: Parker R, organizador. Políticas, instituições e Aids: enfrentando a epidemia no Brasil. Rio de Janeiro: Associação Brasileira Interdisciplinar de Aids; 1997. 177-82.

28. Ávila S. Sustentabilidade em DST/Aids: caminhos para uma saúde possível. In: Ministério da Saúde. Secretaria de Políticas de Saúde. Coordenação Nacional de DST e Aids. Aids e sustentabilidades. Sobre as ações das organizações da sociedade civil. Brasília (DF); 2001.

29. Paiva V, Pupo L, Barboza R. O direito à prevenção e os desafios da redução da vulnerabilidade ao HIV no Brasil. Rev Saúde Pública. 2006; 40 (Supl): 109-19.

30. Ministério da Saúde. Gestão Municipal de Saúde. Leis normas e portarias atuais. Rio de Janeiro; 2001.

31. Silva CL. ONGs/Aids, intervenções sociais e novos laços de solidariedade social. Cad Saúde Pública. 1998, 14 (Supl 2): 129-39.

32. Silva CGM. O significado de fidelidade e as estratégias para prevenção da Aids entre homens casados. Rev Saúde Pública. 2002; 36 (Supl 4): 40-9.

33. Ministério da Saúde. Secretaria de Vigilância em Saúde. Programa Nacional de DST e AIDS. Plano Estratégico Programa Nacional de DST e Aids, 2005. Brasília (DF); março 2005. Disponível em: http://www.Aids.gov.br/ [2006 set 10].

34. Silva NEK, Alvarenga AT, Ayres JRCM. Aids e gravidez: os sentidos do risco e o desafio do cuidado. Rev Saúde Pública 2006; 40: 474-81.

35. Ayres JR. Sujeito: intersubjetividade e práticas de saúde. Ciênc Saúde Coletiva. 2001; 6: 63-72.

Recebido em 2 de dezembro de 2005

Versão final apresentada em maio 12 de maio de 2006

Aprovado em 28 de junho de 2006 